\title{
RANAVIRUS-ASSOCIATED MORBIDITY AND MORTALITY IN A GROUP OF CAPTIVE EASTERN BOX TURTLES (TERRAPENE CAROLINA CAROLINA)
}

\author{
Ryan De Voe, D.V.M., Kyleigh Geissler, D.V.M., Susan Elmore, M.S., D.V.M., David Rotstein, \\ D.V.M., M.P.V.M., Dipl. A.C.V.P., Greg Lewbart, M.S., V.M.D., Dipl. A.C.Z.M., and James Guy, \\ D.V.M., Ph.D.
}

\begin{abstract}
Seven captive eastern box turtles (Terrapene carolina carolina) from a large collection of North American chelonians in North Carolina became acutely ill in the fall of 2002. Five of the turtles died. Clinical signs included cutaneous abscessation, oral ulceration or abscessation (or both), respiratory distress, anorexia, and lethargy. The predominant postmortem lesion was fibrinoid vasculitis of various organs, including skin, mucous membranes, lungs, and liver. No inclusion bodies were detected by histopathology or electron microscopy of formalin-fixed tissue. An iridovirus was isolated from tissues obtained postmortem from two of the box turtles that died. The virus was characterized by electron microscopy, polymerase chain reaction, and sequence analysis of a portion of the major capsid protein as a member of the genus Ranavirus.

Key words: Eastern box turtle, Terrapene carolina carolina, iridovirus, Ranavirus, vasculitis.
\end{abstract}

\section{INTRODUCTION}

Members of the Iridoviridae are large, icosahedral, enveloped DNA viruses that infect a wide range of invertebrate and ectothermic vertebrate species. The Iridoviridae include five genera: Iridovirus, Chloriridovirus, Lymphocystivirus, Ranavirus, and "goldfish virus-1-like viruses." In general, Iridovirus sp. and Chloriridovirus sp. infect invertebrates whereas the remaining genera infect ectothermic vertebrates. ${ }^{9}$ However, this division has not proven to be definite because infections caused by members of the genus Iridovirus have recently been documented in reptiles. ${ }^{14}$ Unclassified iridoviruslike viruses have also been associated with erythrocytic inclusions in fish, amphibians, and reptiles. ${ }^{9,13,21}$

There is a disparity in the severity of disease caused by the two genera of iridoviruses most commonly infecting vertebrate species. Lymphocystivirus infections in fish cause proliferative dermal lesions that are usually self-limiting and rarely associated with mortality. ${ }^{9}$ In contrast, infection with Ranavirus sp. can result in high morbidity and mortality in susceptible species and is responsible for epizootics in both wild and captive fish and amphibians. ${ }^{2,16}$ Frog virus-3 (FV3) is the type species of the genus Ranavirus and can be pathogenic to

From the Departments of Clinical Sciences (De Voe, Lewbart) and Population Health and Pathobiology (Geissler, Elmore, Rotstein, Guy), College of Veterinary Medicine, North Carolina State University, 4700 Hillsborough Street, Raleigh, North Carolina 27606, USA. Correspondence should be directed to Dr. De Voe. frogs and toads at various life stages. Other members of the genus include the epizootic hematopoietic necrosis virus group and the Santee-Cooper virus group, both of which are important pathogens of fish. ${ }^{4}$ Many other ranaviruses have been described that cause significant disease in both wild and captive amphibians and fish. . $, 6,8,21$

Ranaviruses may infect multiple species from different classes. For example, the Bohle iridovirus, a ranavirus that is highly pathogenic to a variety of species of young amphibians, is also experimentally pathogenic to barramundi (Lates calcarifer) and tilapia (Oreochromis massambicus). ${ }^{6}$ Naturally occurring infections of both red-legged frogs (Rana aurora) and stickleback fish (Gasterostelus aculeatus) by FV3 have been described. ${ }^{15}$

Ranaviruses can cause disease in reptiles. They are known to infect various species of chelonians and at least one species of snake. In Mediterranean tortoises (Testudo graeca) and a gopher tortoise (Gopherus polyphemus), pathologic lesions associated with ranavirus infection were comparable. In the Mediterranean tortoises, multifocal necrosis and heterophilic inflammation of the tongue, oral cavity, pharynx, esophagus, intestines, and cloaca were present. ${ }^{11,18}$ The gopher tortoise displayed similar lesions in its pharynx and esophagus but also had severe necrotizing tracheitis and pneumonia. ${ }^{20} \mathrm{Cy}-$ toplasmic, basophilic inclusion bodies associated with the lesions were detected in both cases. In one report on a ranavirus outbreak in $T$. graeca, a group of seven animals was affected with $100 \%$ mortality. ${ }^{18}$ Ranavirus-associated disease is also described in green tree pythons (Morelia viridis) illegally im- 
ported into Australia from New Guinea. Three of 10 snakes died, and chronic ulceration of the nasal mucosa, necrotizing inflammation of the pharyngeal submucosa, and periacinar degeneration and necrosis of the liver were found. ${ }^{12} \mathrm{~A}$ ranavirus previously was identified in eastern box turtles (Terrapene carolina carolina), but specific circumstances of the infection were not reported; this virus has been referred to as turtle virus-3 (TV3).,16 Other iridoviruses, likely to be members of the genus Ranavirus, have been implicated in causing disease in soft-shelled turtles and chameleons. ${ }^{3,7}$ However, these isolates have not been characterized well enough to assign to a genus.

This case series documents ranavirus isolation and characterization from two adult eastern box turtles in a group of seven experiencing significant morbidity and mortality.

\section{CASE REPORTS}

The affected eastern box turtles ( $T$. carolina carolina) were from a privately owned group of over 100 turtles. The majority were eastern box turtles, but there were numerous aquatic North American species, such as painted turtles (Chrysemys picta subsp.), sliders (Trachemys scripta subsp.), and mud turtles (Kinosternon spp.). The majority of the turtles were housed in outdoor pens. Most enclosures contained groups of mixed species. All pens had ponds that were filled with well water from the property or with municipal water. The ponds were made with either plastic pond liners or sealed concrete. The pens in which the sick turtles originated were approximately 54 and $90 \mathrm{~m}^{2}$ respectively. In addition to food items foraged in the pens, the box turtles were offered canned dog food and a variety of fruits and vegetables. The incidence of disease in the group was historically low and sporadic. Many of the turtles have been captive a long time, some more than 30 yr. An outbreak of suspected herpesvirus infection with $100 \%$ mortality in the clinically affected turtles was observed in the group $7 \mathrm{yr}$ earlier, but no significant health problems had been noted since.

All cases occurred between 10 September 2002 and 17 October 2002. Seven box turtles were involved in this disease outbreak. Six of them were wild caught and relatively new in the collection, with the most recently acquired animal added 6 mo before the outbreak. These box turtles were from the same outside pen, which also housed a pair of painted turtles. The remaining turtle was from a pen of six long-term captive eastern box turtles, which had been in the collection from 10 to $>40 \mathrm{yr}$. This pen was adjacent to the pen housing the majority of the affected turtles. The likelihood of direct contact between turtles in adjoining pens was remote, but frogs were noted to pass freely between the pens.

Five of the affected turtles were examined; two died before they could be examined. Clinical signs observed in the live turtles included cutaneous abscesses (5/5), oral erosions or abscessation (or both) $(5 / 5)$, and respiratory distress (3/5); one turtle presented with the aforementioned clinical signs as well as severe unilateral conjunctivitis and cellulitis of the head and neck. The skin abscesses were multifocal, discrete, slightly raised ulcerated nodules 1$4 \mathrm{~mm}$ in diameter, and covered by a yellow-gray crust encircled by a pale rim (Fig. 1). Dyspnea was observed in all terminal animals. Complete blood counts and plasma biochemistry were performed at least once on all turtles examined. Consistently elevated values were seen in urea (3/5), aspartate aminotransferase (3/5), creatine kinase (4/5), and lactate dehydrogenase $(5 / 5)$. Toxic changes were reported in the heterophils of all turtles that died. Other clinical pathology findings were variable and nonspecific (Table 1).

Various treatment regimens were attempted. All turtles received supportive care with parenteral fluids (lactated Ringer's solution injection USP, 0.9\% sodium chloride injection USP [Baxter Healthcare Corp., Deerfield, Illinois 60015, USA], and 5\% Dextrose Injection USP [Abbott Laboratories, Chicago, Illinois 60064, USA] combined in equal volumes, s.c., i.v., or intracoelomically) as well as nutritional support provided via tube feeding. Other therapeutics used included ceftazidime (Fortaz, Baxter Healthcare Corp.; 20 mg/kg, i.m., q 72 hr), enrofloxacin (Baytril, Bayer Corp., Shawnee Mission, Kansas 66201, USA; $5 \mathrm{mg} / \mathrm{kg}$, s.c. or i.m., s.i.d.), clindamycin (Abbott Laboratories; $10 \mathrm{mg} /$ kg, i.m., s.i.d.), acyclovir (Zovirax, GlaxoSmithKline, Research Triangle Park, North Carolina 13398, USA; $80 \mathrm{mg} / \mathrm{kg}$, p.o., s.i.d.), interferon (Schering Corp., Kenilworth, New Jersey 07033, USA; $300 \mathrm{IU} / \mathrm{kg}$, p.o., s.i.d.), flurbiprofen (Pacific Pharma, Irvine, California 92612, USA; topically in the affected eye, q 12-24 hr), and triple antibiotic ophthalmic ointment (Bausch \& Lomb Pharmaceuticals Inc., Tampa, Florida 33637, USA; topically in the affected eye q 12-24 hr). Not all therapeutics were administered to all turtles. Therapy did not seem to alter the course of the disease significantly.

\section{Gross necropsy and histologic findings}

All five turtles that died were necropsied within $24 \mathrm{hr}$ of death. Representative tissue sections were 


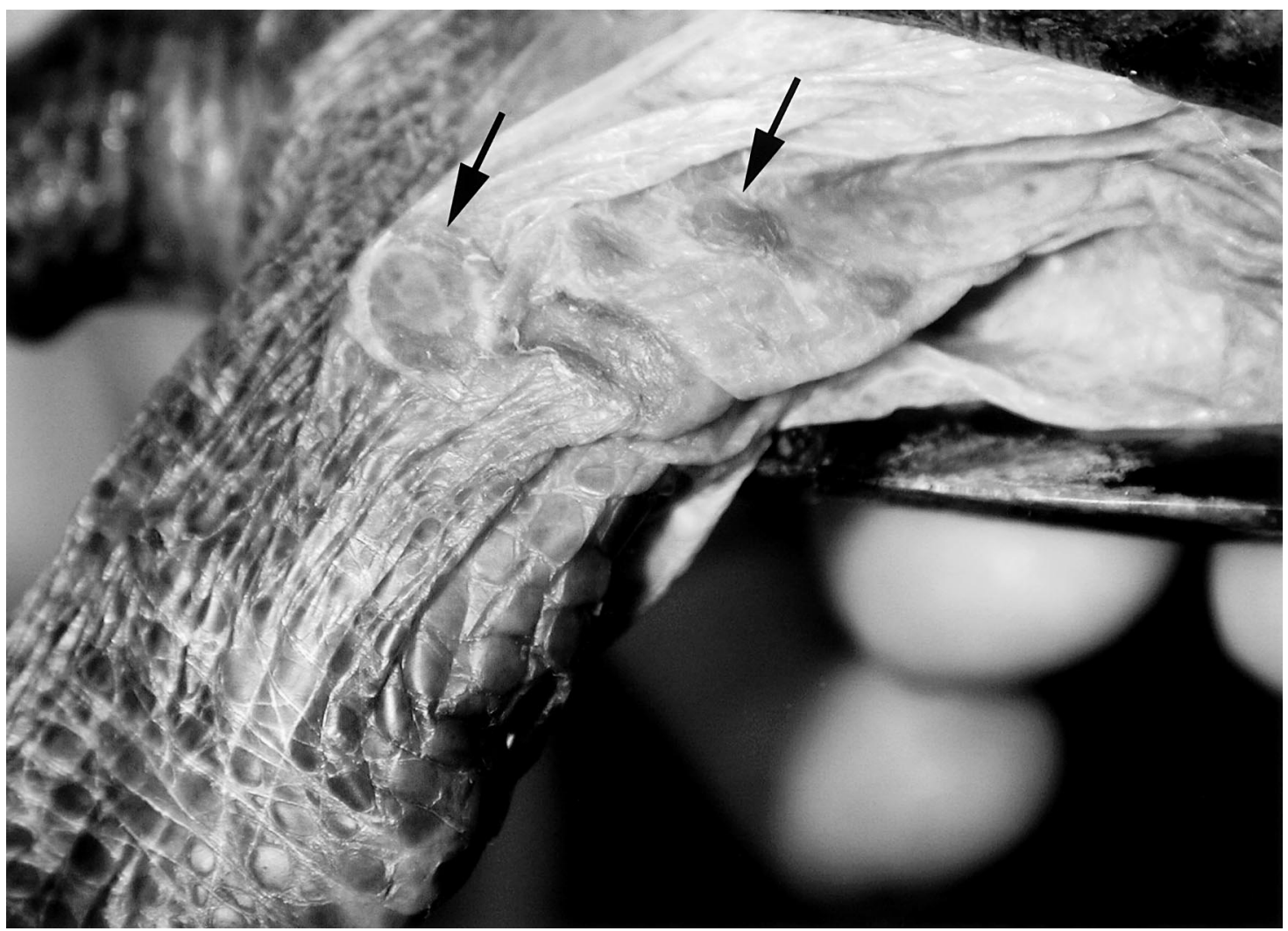

Figure 1. Cutaneous abscessation on the right forelimb of an eastern box turtle from which ranavirus was isolated. Discrete abscesses are indicated with black arrows.

placed in $10 \%$ neutral buffered formalin, processed and sectioned at $5 \mu \mathrm{m}$, and stained with hematoxylin and eosin. Special stains for bacteria and fungi were applied as needed. All turtles were in fair body condition at the time of death. The necropsy findings were similar in all turtles examined. Gross findings included the previously described cutaneous and mucosal lesions, hyperemic and edematous lungs, splenomegaly, and enlarged, yellow livers. Microscopically, fibrinoid vasculitis of the integument, mucous membranes, liver, and lungs was a consistent finding among the animals (Fig. 2). Other organs with fibrinoid vasculitis included the eye $(1 / 5)$, spleen (2/5), stomach (2/5), intestines and colon (2/5), kidney (2/5), and heart and great vessels $(1 / 5)$. Inclusion bodies were not observed in any of the examined tissues.

Heterophilic tracheitis and chronic pancreatitis were present in individual turtles. Gastritis associated with nematodiasis was observed in two animals. Hepatic lipidosis was evident in all necropsied animals.

Aerobic bacterial culture of representative tissues resulted in a variety of isolates. Corynebacterium and Bacillus species were cultured from coelomic swabs taken postmortem from the first two turtles to die. Liver and spleen were cultured from the remaining three turtles postmortem, yielding Enterococcus fecalis (group D) from two. Antemortem cultures of the skin lesions were obtained on five of the seven turtles involved in the outbreak. Pseudomonas aeruginosa and an alpha-hemolytic Staphylococcus species were cultured from the skin lesions of one individual. All samples for skin cultures obtained antemortem were collected before the beginning of antibiotic therapy. All turtles that died received antibiotics before death. Fungal culture of the skin lesions from one turtle yielded a light growth of Absidia sp. No anaerobic bacteria were isolated from any of the sampled tissues.

Special stains were also used to rule out various infectious agents, including Macchiavello for Chlamydophila sp., Gram's for bacteria, Feulgen for viral DNA, Giemsa for bacteria and protozoa, and Gomori's Methenamine Silver (GMS) for fungi. The GMS stain was positive for fungal hyphae as- 


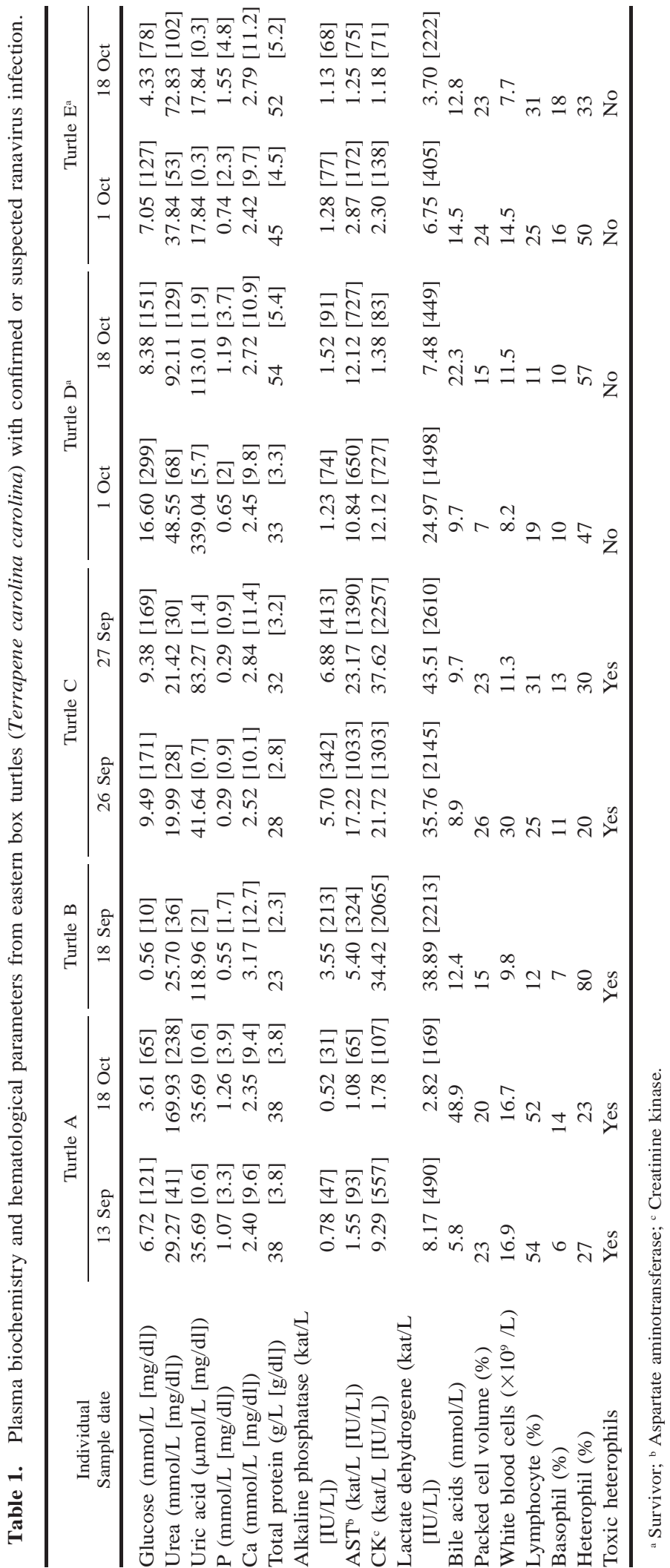



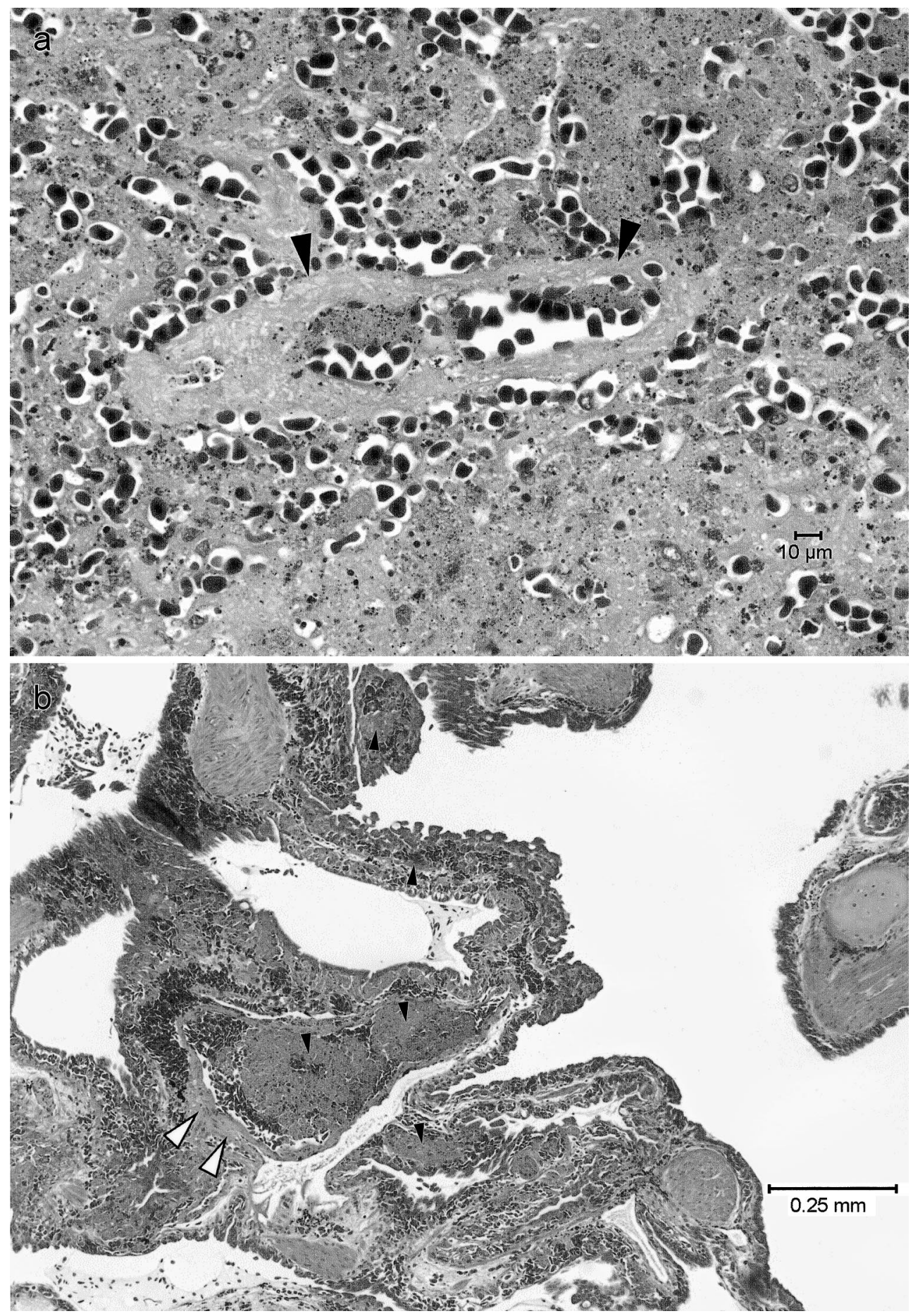

Figure 2. a. Photomicrograph of spleen from an eastern box turtle with ranaviral infection, showing widespread coagulative necrosis of lymphoid and stromal elements. Fibrinoid vasculitis characterized by hyalinized vessel walls with cellular debris is shown (black arrows). Fibrin is observed within the lumen of the vessel. H\&E, $\times 200$. b. Photomicrograph of lung from an eastern box turtle with ranaviral infection. Fibrinoid vasculitis is observed (open arrows), as well as multifocal intravascular thromboses of variably sized vessels (black arrows). H\&E, $\times 40$. 
sociated with the skin lesions in one animal. The organisms were described as nonbranching, septate hyphae with roughly parallel walls consistent with, but not distinct to, an Absidia species. A Chlamydophila sp. antigen-capture enzyme-linked immunosorbent assay of pooled swabs taken from the liver, spleen, skin, and coelom in one animal was negative.

\section{Virology}

Liver, spleen, skin, tongue, and coelomic fluid were submitted for virus isolation from two turtles at necropsy. Oral swabs were collected from the two surviving turtles. Toad kidney (TK) cells were obtained from American Type Culture Collection. TK cells were grown at $23^{\circ} \mathrm{C}$ in a growth medium consisting of Roswell Park Memorial Institute (RPMI) media 1640 (GIBCO BRL, Grand Island, New York 14072, USA) and 10\% fetal bovine serum (FBS).

Tissues from two of seven affected turtles were prepared as $10 \% \mathrm{wt} / \mathrm{vol}$ suspensions in RPMI supplemented with $1 \%$ FBS. Tissues were homogenized, clarified by centrifugation, filtered through $0.45 \mu \mathrm{m}$-diameter membrane pores, and inoculated onto confluent monolayers of TK cells. Swab samples were processed similarly; swabs were discarded, the resultant fluid was clarified, filtered, and inoculated onto TK cells. Inoculated cell cultures were maintained in RPMI supplemented with $1 \%$ FBS, incubated at $23^{\circ} \mathrm{C}$, and examined daily for cytopathic effect.

The box turtle isolate was harvested from infected cells and partially purified. Cell culture supernatant fluid was clarified by centrifugation (10,000 rpm for $20 \mathrm{~min})$ in a Sorvall RC5B Plus centrifuge (Kendro Laboratory Products, Asheville, North Carolina 28806, USA). Clarified supernatant fluid was layered onto a $30 \%(\mathrm{wt} / \mathrm{wt})$ cushion of sucrose and centrifuged at $80,000 \mathrm{~g}$ for $2 \mathrm{hr}$. The resultant pellets were resuspended in TNE buffer (0.01 M Tris-hydrochloride [pH 7.4], $0.1 \mathrm{M} \mathrm{NaCl}$, $1 \mathrm{mM}$ ethylenediaminetetraacetic acid).

Viral DNA was extracted from partially purified virus by incubation in $0.5 \%$ sodium dodecyl sulfate followed by phenol-chloroform extraction as described. ${ }^{17}$ Polymerase chain reaction (PCR) protocols and primers (4 and 5) were as previously described for amplification of a portion of the major capsid gene (approximately 500 base pairs) of FV3. ${ }^{16}$ The PCR product was cloned into pUC19 and transformed into competent Escherichia coli strain DH5 (GIBCO BRL) as described. ${ }^{17}$ The DNA was sequenced at the University of North Carolina (Chapel Hill) Automated DNA Sequencing Facility, on a Model 373A DNA Sequencer (Applied Biosystems, Foster City, California 94404, USA) using the Taq DyeDeoxy Terminator Cycle Sequencing Kit (Applied Biosystems). Gene products were confirmed by sequencing both strands.

Virus isolates were obtained from the pooled tissue samples taken from the two turtles. Cytopathic effect was characterized as focal areas of cell rounding in inoculated TK cells from 5 days postinoculation (PI) and was most pronounced at day 8 PI, involving approximately $80 \%$ of the cell monolayer. Both oral swabs were negative for the presence of virus.

Electron microscopic examination of negatively stained cell culture supernatant fluid revealed icosahedral particles approximately $150 \mathrm{~nm}$ in diameter, morphologically consistent with iridovirus virions (Fig. 3). Thin-section electron microscopy of infected TK cells disclosed clusters of iridoviruslike particles within the cytoplasm. Some virus particles acquired an outer envelope by budding through the plasma membrane (Fig. 4). Electron microscopic examination of formalin-fixed splenic tissue from one turtle did not reveal virus particles associated with lesions.

The DNA obtained from the partially purified box turtle isolate was amplified in a PCR assay using synthetic primers that were based on the major capsid gene of FV3. The PCR products from each isolate were approximately 500 base pairs in size. No product was observed when DNA was harvested from uninfected TK cells and amplified by PCR.

Sequence analysis of the cloned PCR product (495 base pairs) revealed a $99 \%$ sequence identity between the box turtle isolate and the major capsid gene of FV3 and TV3 (data not shown). Similarly, the deduced amino acid sequence revealed an identity of 98\% (161/164 amino acids) with the major capsid protein of FV3 and TV3.

\section{DISCUSSION}

This is not the first description of a ranavirus isolated from an eastern box turtle. TV3 was originally recovered from an eastern box turtle, is frequently referred to in the literature, and is used in comparative studies of ranaviruses. ${ }^{16}$ However, no description of the circumstances regarding isolation of this virus exists in the literature. Therefore, this is the first report on the clinical aspects of presumptive ranavirus infection in a captive population of eastern box turtles. This documentation is important because members of the genus Ranavirus appear to be variably pathogenic according to factors such as species and age. FV3 causes subclinical infections in adult Rana pipiens but is known 


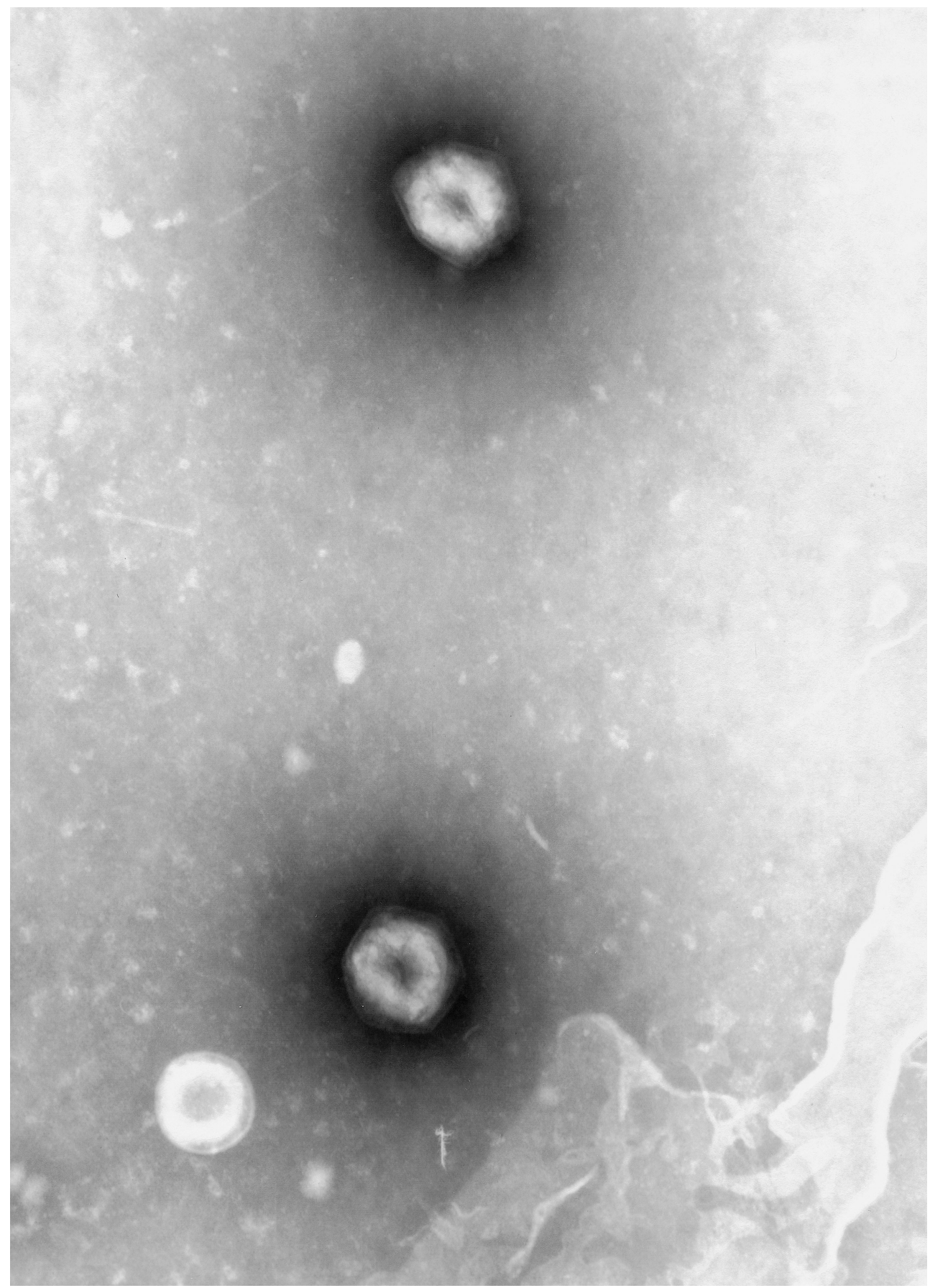

Figure 3. Transmission electron micrograph of supernatant fluid from a cell culture inoculated with box turtle tissue. Icosahedral viral particles, approximately $150 \mathrm{~nm}$ in diameter, morphologically consistent with an iridovirus are observed. $\times 50,000$. 


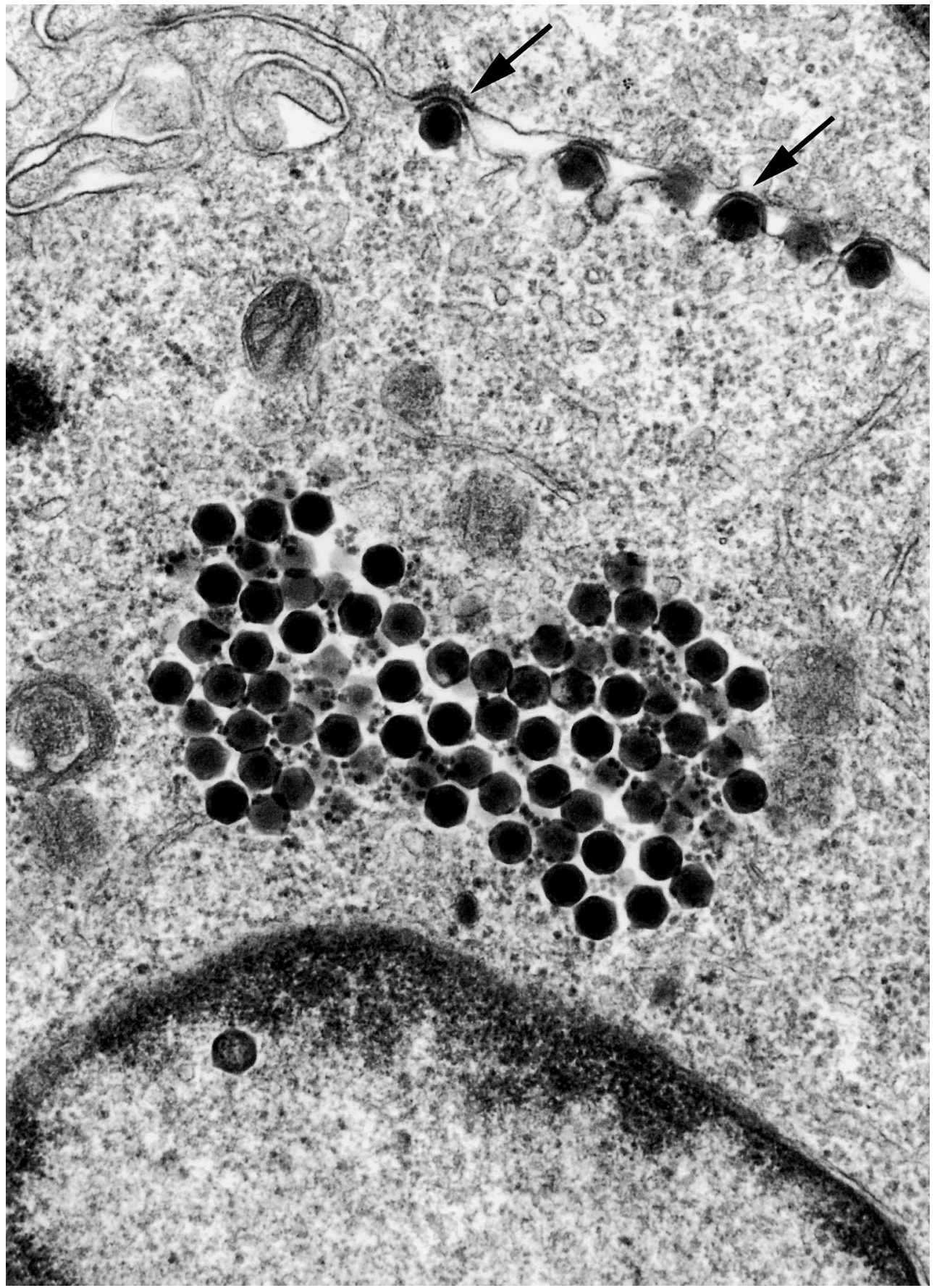

Figure 4. Transmission electron micrograph of an infected toad kidney cell from culture inoculated with box turtle tissue. A cluster of icosahedral viral particles, approximately $150 \mathrm{~nm}$ in diameter, is observed in the cytoplasm. Multiple viral particles are seen budding through the plasma membrane (black arrows). Morphology and cytoplasmic assembly site are consistent with an iridovirus. $\times 20,000$. 
to be experimentally pathogenic in younger life stages of frogs and Fowler's toads (Bufo woodhousei). ${ }^{4,9}$ The information presented in this study suggests that under appropriate environmental or host circumstances, this ranavirus may be capable of causing considerable morbidity and mortality in eastern box turtles.

The virus isolate from the turtles in this case series was amplified with primers previously shown to be specific for the major capsid protein of iridoviruses in the Ranavirus genus. ${ }^{15}$ This confirms the isolate as a member of the genus Ranavirus. Sequencing of the amplified product demonstrated a $99 \%$ nucleotide sequence and a $98 \%$ amino acid identity with TV3 and FV3. Therefore, this isolate appears to be identical with the previously characterized TV3 isolate. A $100 \%$ identity exists between FV3 and TV3 within the same region of the major capsid protein. ${ }^{16}$ At present, there is some controversy regarding classification of ranaviruses. Isolates within the genus Ranavirus show greater than $75 \%$ identity within the MCP gene. ${ }^{5}$ Many isolates share greater than $90 \%$ identity with $\mathrm{FV} 3$ at the molecular level, yet some differ in regard to host range and other characteristics such as restriction fragment profiles. ${ }^{12}$ Therefore, what classifies a ranavirus as a strain of a previously described virus or a new species is not uniformly agreed upon. ${ }^{4}$ Characterization beyond sequencing was not performed on this box turtle isolate.

Differential diagnoses for the clinical signs observed in these box turtles include herpesvirus infection as well as systemic bacterial and fungal infection. The most common signs of herpesvirus infection in chelonians are rhinitis, conjunctivitis, and stomatitis. ${ }^{19}$ Stomatitis was seen in all the affected box turtles, and at least one suffered from severe conjunctivitis. These findings combined with the history of a previously documented outbreak in this population of turtles initially made herpesvirus infection a top differential diagnosis. Multifocal cutaneous abscessation is not uncommon in debilitated, immunosuppressed, or septic chelonians. In many cases, internal abscesses accompany the cutaneous lesions. A variety of bacterial and fungal species are reported to be associated with septicemia-abscessation in chelonians, including Pseudemonas aeruginosa, Dermatophilus, and Aspergillus sp. ${ }^{1,10}$ The exact role of the isolated bacteria and fungi in the pathogenesis of the observed morbidity and mortality in the affected turtles is not known. It is presumed that although these organisms may have played a role in the disease process, they were most likely secondary invaders. The antemortem cultures of skin lesions were performed before the administration of any therapeutics, but the postmortem culture samples were obtained after treatment with various antimicrobial medications. Therefore, the impact of antimicrobial therapy on the postmortem cultures is not known but could be significant.

The vascular lesions in these turtles could be caused by a variety of systemic infectious diseases. Fibrinoid vasculitis can occur with bacterial septicemia, rickettsial disease, systemic fungal infections as well as other viral infections (e.g., herpesviruses). ${ }^{9}$ The evidence collected does not suggest the presence of another infectious organism that could be responsible for the morbidity and mortality in this group of turtles. However, the pathologic changes are relatively nonspecific, and the presence of another pathogen cannot be definitively ruled out.

Complete blood counts and plasma chemistry panels were not helpful in establishing prognosis in these cases. Toxic heterophils were detected in all turtles that died; otherwise, changes were nonspecific and did not correlate with the occurrence of mortality or severity of lesions postmortem.

The reason all the box turtles in one pen and only a single turtle in the rest of the collection were affected by disease is open to speculation. It is possible that the newer turtles were immunologically naive and were not able to respond effectively to viral infection, whereas the other turtles had developed some degree of immunity.

The clinical signs and pathologic changes observed in these box turtles differ from those described in other chelonians with iridovirus infections. Previous reports on infection in a gopher tortoise and a group of Hermann's tortoises document mucosal lesions and signs of respiratory disease, as was seen in these box turtles. ${ }^{11,18,20}$ Cutaneous abscessation as a clinical feature of iridovirus infection has not been reported in chelonians and if induced by the virus appears unique to this outbreak. Fibrinoid necrosis was the most prominent histologic lesion of various organs in the box turtle outbreak. Vascular lesions have not been specifically described in other chelonians, though gross petechial hemorrhages are reported with iridovirus infections in soft-shelled turtles. ${ }^{3}$ Finally, basophilic inclusion bodies were observed in affected tissues from the gopher tortoise and the Hermann's tortoises. ${ }^{11,18,20}$ No inclusion bodies were seen in any of the tissues examined from these box turtles.

The diagnosis of ranaviral infection is supported by the isolation of virus from affected tissues and systemic lesions consistent with a viral infection. We were not able to directly observe viral particles 
within lesions by electron microscopic examination of formalin-fixed splenic tissue. Immunostaining was not performed nor were Koch's postulates fulfilled using the virus isolate. Therefore, we cannot definitively state that the outbreak of disease seen in this group of turtles was caused by the ranavirus isolated, although the evidence is highly suggestive. Since documentation of this outbreak, another wild eastern box turtle that exhibited comparable clinical signs was seen at North Carolina State University's College of Veterinary Medicine for rehabilitation. The turtle ultimately succumbed, and an iridovirus was isolated from affected tissues. Microscopic examination of tissues from this turtle revealed findings similar to those reported in this case series. Efforts are currently underway to develop reagents that will allow immunohistochemical staining of tissues for this virus. This will allow for retrospective examination of tissue from this outbreak, as well as future diagnostic investigations. Other techniques that could potentially demonstrate the presence of virus associated with lesions include in situ hybridization as well as electron microscopic examination of properly obtained and fixed tissues.

Acknowledgments: We thank Dr. Albert Harris, Department of Biology, University of North Carolina-Chapel Hill, and Dr. Elizabeth H. Harris, Department of Biology, Duke University. We also thank Shane Christian for technical support in the management of these cases and data compilation and Ms. Meiko Nishiyori for providing funding for the PCR and DNA sequencing of the viral isolate.

\section{LITERATURE CITED}

1. Bemis, D. A., C. S. Patton, and E. C. Ramsay. 1999. Dermatophilosis in captive tortoises. J. Vet. Diag. Invest. 11: 553-557.

2. Bollinger, T. K., J. Mao, D. Schock, R. M. Brigham, and V. G. Chinchar. 1999. Pathology, isolation, and preliminary molecular characterization of a novel iridovirus from tiger salamanders in Saskatchewan. J. Wildl. Dis. 35: 413-429.

3. Chen, Z., J. Zheng, and Y. Jiang. 1999. A new iridovirus isolated from soft-shelled turtle. Virus Res. 63: 147-151.

4. Chinchar, V. G. 2002. Ranaviruses (family Iridoviridae): emerging cold-blooded killers. Arch. Virol. 147: 447-470.

5. Chinchar, V. G., and J. Mao. 2000. Molecular diagnosis of iridovirus infections in cold-blooded animals. Semin. Avian Exotic Pet Med. 9: 27-35.

6. Cullen, B. R., and L. Owens. 2002. Experimental challenge and clinical cases of Bohle iridovirus (BIV) in native Australian anurans. Dis. Aquat. Org. 49: 83-92.
7. Drury, S. E. N., R. E. Gough, and I. Calvert. 2002. Detection and isolation of an iridovirus from chameleons (Chamaeleo quadricornis and Chamaeleo hoehnelli) in the United Kingdom. Vet. Rec. 150: 451-452.

8. Drury, S. E. N., R. E. Gough, and A. A. Cunningham. 1995. Isolation of an iridovirus-like agent from common frogs (Rana temporaria). Vet. Rec. 137: 72-73.

9. Essbauer, S., and W. Ahne. 2001. Viruses of lower vertebrates. J. Vet. Med. B. 48: 403-475.

10. Frye, F. L. 1991. Biomedical and Surgical Aspects of Captive Reptile Husbandry, 2nd ed. Kreiger Publishing, Melbourne, Florida.

11. Heldstab, A., and G. Bestetti. 1982. Spontaneous viral hepatitis in a spur-tailed Mediterranean land tortoise (Testudo hermanni). J. Zoo Anim. Med. 13: 113-120.

12. Hyatt, A. D., M. Williamson, B. E. H. Coupar, D. Middleton, S. G. Hengstberger, A. R. Gould, P. Selleck, T. G. Wise, J. Kattenbelt, A. A. Cunningham, and J. Lee. 2002. First identification of a ranavirus from green tree pythons (Chondropython viridis). J. Wildl. Dis. 38: 239252.

13. Johnsrude, J. D., R. E. Raskin, A. Y. A. Hoge, and G. W. Erdos. 1997. Intraerythrocytic inclusions associated with iridoviral infection in a fer de lance (Bothrops moojeni) snake. Vet. Pathol. 34: 235-238.

14. Just, F., S. Essbauer, W. Ahne, and S. Blahak. 2001. Occurrence of an invertebrate iridescent-like virus (Iridoviridae) in reptiles. J. Vet. Med. B. 48: 685-694.

15. Mao, J., D. E. Green, G. Fellers, and V. G. Chinchar. 1999. Molecular characterization of iridoviruses isolated from sympatric amphibians and fish. Virus Res. 63: 45-52.

16. Mao, J., R. P. Hedrick, and V. G. Chinchar. 1997. Molecular characterization, sequence analysis, and taxonomic position of newly isolated fish iridoviruses. Virology 229: 212-220.

17. Mao, J., T. N. Tham, G. A. Gentry, A. Aubertin, and V. G. Chinchar. 1996. Cloning, sequence analysis, and expression of the major capsid protein of the iridovirus, frog virus 3. Virology 216: 431-436.

18. Marschang, R. E., P. Becher, H. Posthaus, P. Wild, H. J. Thiel, U. Muller-Doblies, E. F. Kaleta, and L. N. Bacciarini. 1999. Isolation and characterization of an iridovirus from Hermann's tortoises (Testudo hermanni). Arch. Virol. 144: 1909-1922.

19. Schumacher, J. 1996. Viral diseases. In: Mader, D. R. (ed.). Reptile Medicine and Surgery. W. B. Saunders Co., Philadelphia, Pennsylvania. Pp. 224-234.

20. Westhouse, R. A., E. R. Jacobsen, R. K. Harris, K. R. Winter, and B. L. Homer. 1996. Respiratory and pharyngo-esophageal iridovirus infection in a gopher tortoise (Gopherus polyphemus). J. Wildl. Dis. 32: 682-686.

21. Zhang, Q., F. Xiao, Z. Li, J. Gui, J. Mao, and V. G. Chinchar. 2001. Characterization of an iridovirus from the cultured pig frog Rana grylio with lethal syndrome. Dis. Aquat. Org. 48: 27-36.

Received for publication 28 April 2003 